\title{
Time-Dependent Seismology
}

\author{
Don L. Anderson and J. H. Whitcomb \\ Seismological Laboratory, California Institute of Technology. Pasadena. California 91109
}

\begin{abstract}
The time variation of crustal velocities in tectonic regions is most reasonably attributed to stressinduced variations in crack porosity. The decrease in $V_{p} / V$, before earthquakes is due primarily to a large decrease in $V_{p}$. This supports the Nur dilatancy hypothesis but not the effective stress hypothesis. New data from the San Fernando region verify the $V_{p}$ drop, show that this drop cannot be entirely due to source depth effects, and give strong support to the explanation of material property, or path effect, rather than source effect variations. Calculations show that the crack-widening model works even for midcrustal depths in saturated rock. Narrow cracks of low aspect ratio are required to satisfy the velocity and uplift constraints. The recovery of velocity prior to fracture can be due to fluid flow or crack closure. The $t \sim L^{2}$ relation does not require diffusion. Diffusion of groundwater or crack closure leads to increased pore pressure and rock weakening. Observations of gravity, conductivity, and crustal distortions along with velocities should narrow the choice of models. The crust in regions of thrust tectonics is probably always dilatant to some degree. The aftershock region is smaller than the anomalous velocity region, which in turn must be smaller than the dilatant region. A simple relationship is derived for the relative sizes of the anomalous and aftershock regions.
\end{abstract}

\section{INTRODUCTION}

Until quite recently, seismologists have assumed that seismic velocities in the crust are not a function of time. However, since 1962, Soviet seismologists have been reporting on unusual variations in seismic velocities prior to local earthquakes [Kondratenko and Nersesov, 1962]. The $V_{p} / V_{s}$ ratio was observed to drop for a period of time that increased with the magnitude of the impending earthquake. These basic observations were reproduced for small New York State earthquakes by Lamont-Doherty Geological Observatory [Aggarwal et al., 1973] and larger California earthquakes by California Institute of Technology [Whitcomb et al., 1973; Stewart, 1973]. Savarensky [1968] and Aggarwal et al. [1973] suggested that the main effect was due to an increase in $V$, during the anomalous period. However, the San Fernando study [Whitcomb et al., 1973] showed that the $V_{p} / V_{s}$ anomaly was due to a large decrease in $V_{p}$ and a smaller decrease in $V_{g}$. This observation combined with the large spatial extent and time scale of the velocity anomaly for the San Fernando event seemed to give support to the dilatancy-diffusion model as formulated by Nur [1972], Whitcomb et al. [1973], and Anderson and Whitcomb $[1973 a, b]$. The monitoring of quarry blasts in California (H. Kanamori and D. Hadley, personal communication, 1974) and measurement of $P$ delays from teleseismic events [Stewart, 1973; Kanamori and Chung, 1974; Wyss and Holcomb, 1973] give additional support to the idea that crustal $\boldsymbol{P}$ wave velocities, at least in tectonic regions, can change with time.

There have been two hypotheses put forward to explain temporal velocity changes. The first hypothesis [Nur, 1972] attributes the onset of the anomaly to new crack formation; the second hypothesis attributes it to an increase in effective stress [Aggarwal et al., 1973]. The predictions of the two hypotheses are quite different and easily checked with present field and laboratory data. Nur [1972] showed that the low values of $V_{p} / V_{s}$ could be matched by dry rocks, even of low porosity, but not by water-saturated rocks and therefore proposed that the observed anomalies were due to the opening of dry cracks. Experimental [Nur and Simmons, 1969] and theoretical [Walsh, 1969] results indicate that both $V_{p}$ and $V_{B}$ decrease with an increase in porosity whether cracks are

Copyright $\odot 1975$ by the American Geophysical Union. saturated or dry. However, the $V_{p} / V_{s}$ ratio increases or is constant with crack porosity in saturated rocks and decreases in dry rock. For a rock with a given porosity, $V_{p} / V_{s}$ is lower for the dry rock than for the saturated rock. These observations are all consistent with the USSR and California data but not with the suggestion [Aggarwal et al., 1973] that the $V_{p} / V_{s}$ decrease is due to an increase in both $V_{p}$ and $V_{8}$.

The San Fernando event [Whitcomb et al., 1973] showed that the size of the velocity decrease was about the same as for smaller earthquakes and that the anomaly time scaled as $L^{2}$. This event also showed that the anomalous zone was much larger than the aftershock zone.

Whitcomb et al. [1973] proposed that the $V_{p}$ and $V_{p} / V_{s}$ anomaly could be due to the widening of preexisting wet cracks, as well as the opening of new dry cracks as proposed by Nur [1972], and that changes in uplift and electrical conductivity and other geophysical parameters would accompany these processes. Scholz et al. [1973] followed this model and correlated anomalies of published data of electrical resistivity, crustal uplifts, and other geophysical parameters with the same magnitude-time relationship as was produced by the velocity anomalies.

The recovery of the velocities prior to the earthquake also has several possible explanations. The simplest is that the newly opened cracks close up just prior to fracture [Brady, 1974]. This seems to be similar to the working hypothesis of the Soviets (D. Griggs and L. Knopoff, personal communication, 1973). One alternative is that water diffuses into the newly opened or widened cracks [Nur, 1972]. This has been termed the dilatancy-diffusion hypothesis [Anderson and Whitcomb, $1973 a, b]$.

\section{Additional Seismic Evidence From the San Fernando Event}

In the previous study [Whitcomb et al., 1973] the events chosen for study were in the epicentral area of the San Fernando event. The study showed that most of the anomaly, if it was interpreted in terms of velocity changes, was due to a decrease in compressional velocity. We now have virtually eliminated the possibility that the low velocity values observed during the precursory anomaly time are due to depth effects. Well-located shallow aftershocks of the San Fernando series give apparent 
$V_{p}$ measured between stations PAS and RVR of $6.3 \mathrm{~km} / \mathrm{s}$, which requires that observed velocities lower than this value cannot be due to a hypocentral depth effect. Although it would be extremely difficult to interpret the data in terms of source effects, they could not be ruled out completely because the events used were in the aftershock region of the San Fernando earthquake.

The $V_{p} / V_{s}$ results from Garm [Sadovsky et al., 1972, also personal communication, 1973] suggested that anomalous values occur only if the seismic source is located in the nearsource region of the impending earthquake. That is, seismic waves originating outside and traveling through the zone apparently do not exhibit an anomalous decrease in $V_{p} / V_{s}$. No subsequent experiment relevant to this very important point has been done except that the results of Whitcomb et al. [1973] imply velocity effects for a region significantly larger than the aftershock zone.

We have now analyzed events originating outside the San Fernando region with ray paths passing through the epicentral region. Figure 1 shows a map of the events (solid squares) and the stations PAS and SWM (triangles). The events used in the previous PAS-RVR experiment are also shown (solid circles), and those producing anomalous velocity measurements are indicated by a large circle. These events define the anomaly time duration.

Figure 2 shows the results of the PAS-SWM experiment and the previous PAS-RVR data. Values in parentheses indicate less certain readings. The velocity anomalies are similar to the previous results. The differences may be related to an $M_{L}=4.3$ earthquake in February 1969 near Palmdale $(29 \mathrm{~km}$ from the PAS-SWM line) and the $M_{L}=5.4$ Lytle Creek event in September 1970 (60 km from the PAS-SWM line). These new results support the idea that the velocity anomaly is a path, rather than a source effect, and that the size of the anomalous region is much greater than the aftershock area. The data are too limited to determine if the effect is anisotropic.

\section{DilatanCY}

The dilatancy theory provides one mechanism for explaining velocity decreases. This is a phenomenon that occurs prior to fracture in laboratory triaxial experiments. Dilatancy is

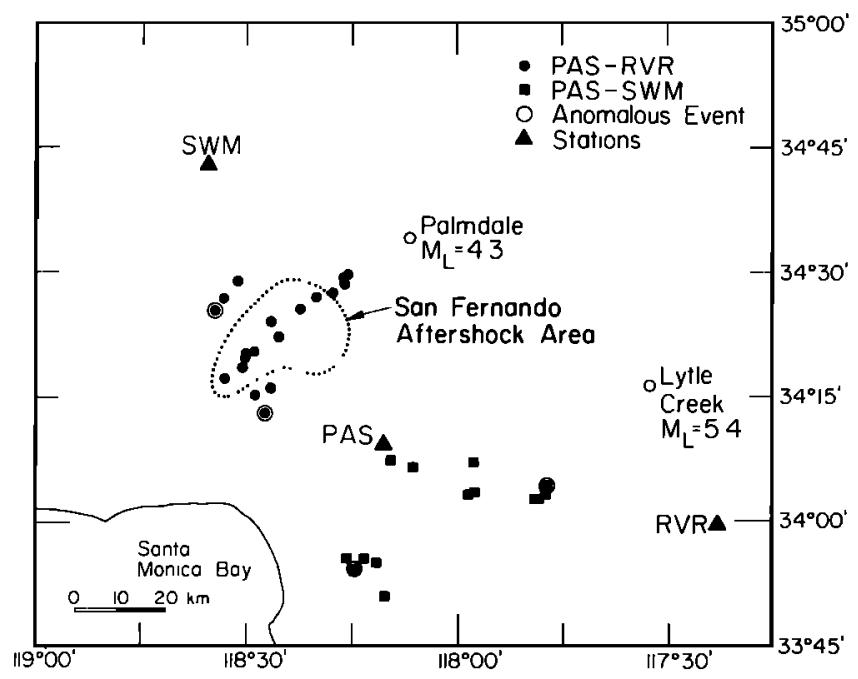

Fig. 1. Map of events and stations used for measuring velocities for the station combinations PAS-SWM (square symbols) and PASRVR (solid circles) [Whircomb et al., 1973]. Events producing anomalously low $V_{p}$ and $V_{p} / V_{s}$ are circled. These events are all between mid-1967 and late 1968 (see Figure 2).
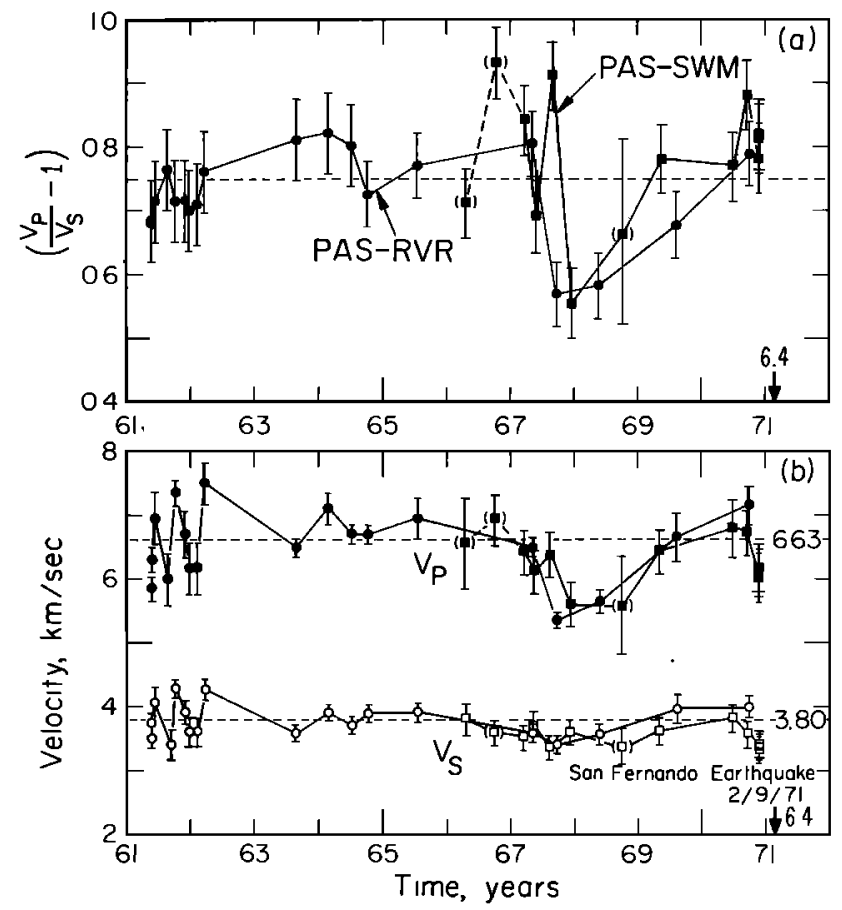

Fig. 2. The variation of $\left(V_{p} / V_{s}-1\right), V_{p}$, and $V_{a}$ before the San Fernando earthquake for the PAS-SWM station combination. Data from the PAS-RVR combination [Whitcomb et al., 1973] are shown for referencing during the same time period.

caused by an increase in porosity, either newly created or stemming from growth of preexisting cracks. During the early stages of dilatancy the pore volume and pore pressure change slowly with applied stress. Just prior to rupture the rate of change of crack volume increases, the pore pressure drops rapidly, the effective stress increases, and the strength of the affected region increases. At shallow depths the cracks eventually expand more than the pore fluid, and the cracks become undersaturated [Whitcomb et al., 1973]. The compressional velocity drops abruptly at this point because of the high compressibility of a rock containing dry or undersaturated cracks. At pressures and temperatures existing at midcrustal depths the decrease of pore pressure results in a decrease in the bulk modulus and the viscosity of the pore fluid [Anderson and Whitcomb, 1973a, b]. When the pore pressure returns to some critical value, either by fluid flow or by crack closure, failure will occur.

We will examine the implications of this hypothesis and also the alternative that crack closure, rather than fluid flow, is responsible for the velocity recovery.

\section{Recovery Phase}

There are at least four possible explanations for the return of $V_{p}$ and $V_{p} / V_{s}$ to near-normal values prior to the earthquake: (1) a reversal of the situation that lead to the anomaly in the first place, i.e., closure of cracks; (2) a redistribution of open cracks toward the fault, leading to crack closure in the bulk of the dilatant volume; (3) flow of water into the newly opened cracks; and (4) creep, solid state diffusion, dislocation motion, or time-dependent strength behavior of the material in the focal region.

The time scales of the above processes would presumably be quite different. In alternatives 1 and 2 one must postulate that crack closure or redistribution is part of the natural sequence of events that follow onset of dilatancy and precede failure. The time scale would be related to the tectonic strain rate and 
would therefore be proportional to other time scales in the tectonic cycle such as repetition rates of earthquakes. In alternative 3 the time scale would be governed by the fluid flow rate in permeable rock and would therefore be a function of permeability, rock compressibility, and fluid viscosity. In alternative 4 the stress field and the rheological properties of the rock control the time scale.

The other geophysical manifestations of the recovery phase could resolve the possibilities. Geodetic, gravity, and leveling data should correlate with the velocity changes. For example, during the accelerated dilatancy phase, the first part of the anomalous period, line lengths and elevation should increase. Gravity should decrease, and electrical conductivity should increase. These changes will slow down as dilatancy hardening sets in. In the diffusion model, elevation should remain stable until adequate fluid pressure is available to weaken the rock and lead to accelerated motions just prior to failure. Electrical conductivity, velocity, and gravity will increase during the recovery phase due to pore filling.

In the crack closure model, geodetic measurements, gravity, and electrical conductivity, as well as velocity, should all reverse the behavior exhibited during the first part of the cycle except possibly in the vicinity of the incipient fracture.

Electrical conductivity changes depend on whether the rock is initially dry or wet and on the magnitude of the dilatancy volume change. Conductivity is generally dominated by conductive pore fluids. Increased crack volume in a dry rock should decrease the conductivity, whereas increased volume in a wet rock should at first increase the conductivity. If the dilatancy volume increase in a wet rock is large, void volume effects may begin to overtake the fluid conduction path effects, and conductivity may turn around and begin to decrease prior to the earthquake.

The recovery mechanism should satisfy the relation, time is approximately proportional to area, discussed by Whitcomb et al. [1973]. Mechanisms 3 and 4 are basically diffusion mechanisms, and therefore $t \sim A \sim L^{2}$. For these alternatives it remains only to show that the constant of proportionality is reasonable. It will be the hydraulic diffusivity on the one hand and a rock viscosity on the other.

In mechanism 1, crack closure, the time scale is dictated by tectonic strain rates, and the anomaly time duration should be some small fraction of the recurrence interval, or the time required to build up from the ambient stress to the failure stress.

\section{Time Duration of the Anomalous Period}

Nur [1972] and Whitcomb et al. [1973] suggested that the seismic velocities should return to normal values on a time scale appropriate to the flow of fluid into the anomalous region from surrounding normal regions. The limited magnitude range and the scatter of the USSR and New York State data did not permit a definite conclusion concerning the relation between earthquake dimension $(L)$ and anomaly time $(t)$. The San Fernando earthquake established the relation as $t$ $\sim L^{2}$ [Whitcomb et al., 1973; Anderson and Whitcomb, 1973a, $b$; Scholz et al., 1973], which could be interpreted in terms of diffusive behavior.

We first investigate the hypothesis that the velocity recovery is due to the diffusion of groundwater into the anomalous region. Anderson and Whitcomb $[1973 a, b]$, using a spherical geometry with water diffusing inward, estimated a hydraulic diffusivity of about $10^{4} \mathrm{~cm}^{2} \mathrm{~s}^{-1}$.

A similar calculation can be performed for the case where vertical cracks in the center of the dilatant area, perhaps due to tension caused by uplift, allow shallow water to flood the dilatant region from the center out. This model is probably more appropriate for explaining the seismic and aftershock data. The time scale and inferred diffusion properties, however, are similar to the calculation referred to above.

There are several ways to test the reasonableness of the diffusion parameters implied by the duration of the anomaly time and hence the interpretation of the recovery mechanism as a diffusion phenomenon. In the Denver and Rangley experiments, earthquake activity was directly related to fluid injection. In the Denver case, earthquakes appeared $5 \mathrm{~km}$ from the well within 1 month of the initiation of injection; in the Rangley experiment, pressure started to rise in a well $1 / 4$ mile from the injection well within about 2 hours (J. Healy, personal communication, 1973). These observations are consistent with the length-time observations for precursors to earthquakes and imply a hydraulic diffusivity of between $10^{4}$ and $10^{5} \mathrm{~cm}^{2} \mathrm{~s}^{-1}$ (Figure 3). Direct measurements at the wellhead of the Denver disposal well have yielded values as high as $2 \times 10^{8} \mathrm{~cm}^{2} / \mathrm{s}$ for the hydraulic diffusivity of the Precambrian horizon at a $3.7-\mathrm{km}$ depth [van Poollen and Hoover, 1970].

Measurements by Brace and Martin [1968] provide another means for estimating the hydraulic diffusivity of dilatant granite. From the time scale and geometry of the experiments (fluid was allowed to enter from one end of a cylindrical sample) one can estimate that the diffusivity near failure was $<2$ $\mathrm{cm}^{2} \mathrm{~s}^{-1}$. In order to scale this to the crust we must take into account differences in fluid viscosity and geometry. With the use of a porosity at fracture of $1.4 \%$ for the crust and a spherical geometry this scales to about $10^{4} \mathrm{~cm}^{2} \mathrm{~s}^{-1}$.

A less obvious test is the migration of aftershocks away from underground nuclear explosions. For example, the aftershock region of the underground explosion Benham increased by $3 \mathrm{~km}$ in 10 days and by $4 \mathrm{~km}$ in 20 days [Hamilton and Healey, 1969], presumably along a preexisting fault. These Benham aftershock points also fall close to the curve for precursory anomalies and give a hydraulic diffusivity close to $10^{4} \mathrm{~cm}^{2} \mathrm{~s}^{-1}$. Other earthquake aftershock characteristics are also consistent with a fluid flow mechanism [Nur and Booker, 1972].

There are also some relevant laboratory data. Short [1966] measured the sonic velocities and permeabilities in lowporosity samples of granodiorite from the Nevada Test Site. Preshock samples had velocities of about $5.8 \mathrm{~km} / \mathrm{s}$ and permeabilities of about $10^{4}$ nanodarcys. Shocked samples had velocities of $2.9 \mathrm{~km} / \mathrm{s}$ and permeabilities of $15 \times 10^{\circ}$ nanodarcys. In the lower-porosity samples, $k \sim V_{p}$; i.e., cracks caused a much larger change in permeability than in velocity.

Semiempirical relationships between permeability, electrical conductivity, and porosity [Brace et al., 1968; Brace and Orange, 1968] suggest that the permeability increases by at least an order of magnitude from the onset of dilatancy to failure. In situ permeabilities probably involve large joints and fractures and therefore may be much larger than laboratory estimates. The above considerations suggest that $10^{4}-10^{5}$ nanodarcys is not an unreasonable estimate of permeability in fractured rock and therefore the diffusional mechanism of velocity recovery cannot be ruled out.

The source of water, however, is not obvious. The extensive fracturing associated with uplift may allow shallow water to migrate to the epicentral region. In this case the velocity anomaly would be annihilated from the center out, and this phenomenon would be consistent with aftershock patterns. If 


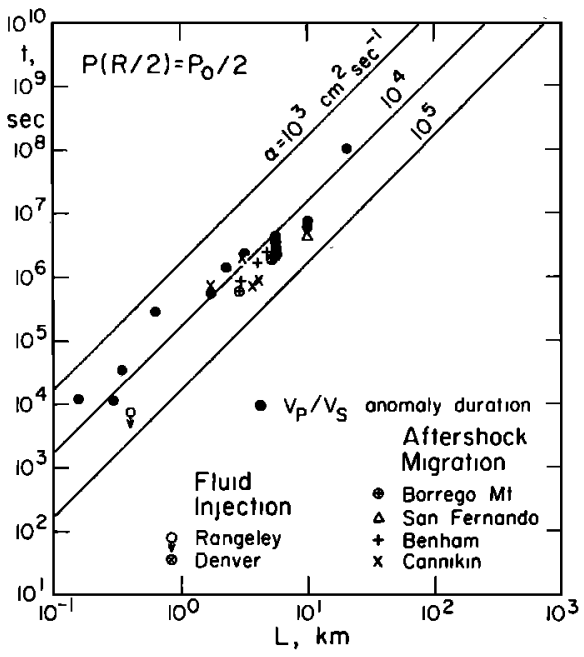

Fig. 3. Characteristic time versus characteristic dimension associated with earthquake precursors, fluid injection, and aftershock migration. The theoretical curves are computed for spherical diffusion and a range of hydraulic diffusivities following Anderson and Whitcomb $[1973 b]$.

water diffuses horizontally from adjacent regions, the velocity anomaly would be annihilated from the periphery toward the center.

\section{Alternate to Diffusion}

The recurrence interval between large Japanese earthquakes [Tsubokawa, 1969] closely satisfies the diffusion relation proposed by Whitcomb et al. [1973] for the duration of the anomaly time. This raises the interesting possibility that the interval between major earthquakes at plate boundaries is mainly governed by the rate of fluid flow into these regions. It is more accepted, however, that recurrence rates of earthquakes are controlled by tectonic strain rates. This would mean that recurrence times only accidently satisfy the pattern observed for anomaly times or that anomaly times are not related to diffusion.

Two well-known empirical seismological relationships are the magnitude-frequency relation [Gutenberg and Richter, 1942]

$$
\log N=a+b M
$$

and the aftershock area-magnitude relation [Utsu and Seki, 1955; Utsu, 1957]

$$
\log A=c+M
$$

where $N$ is the number of events of magnitude $>M$ in a given time interval, $A$ is the aftershock area, and $a, b$, and $c$ are empirical constants. Where statistics are complete, $b \sim-1$. Therefore

$$
\log N \sim-\log A
$$

By writing $N$ as $n / t$, the number $n$ of events per unit time, the recurrence interval for a given magnitude event is $t$; i.e., $n=1$. Therefore

$$
\log t \sim \log A \sim \log L^{2}
$$

where $L$ is a characteristic linear dimension of the earthquake. Obviously, the recurrence relationship combined with the area or fault length relationship implies that

$$
t \sim L^{2}
$$

This relationship does not necessarily imply a diffusion mechanism. It implies only that the number of events of magnitude $M$ in a given area is proportional to the characteristic area of the earthquake, for example, the aftershock area. The time intervals between successive stages in the stress-strain history, such as time between failures (recurrence interval), time between onset of dilatancy and a velocity or resistivity anomaly, or the duration of the anomaly, should all be proportional to one another and to $L^{2}$. When corresponding times from one region to another are compared the scale factor should be related to tectonic strain rates. In seismic regions these only differ by about a factor of 2 or 3 , which is less than the scatter in $t \sim L^{2}$ relations presented by Whitcomb et al. [1973] and Scholz et al. [1973].

\section{Size of the Dilatant Region}

Geodetic studies indicate that the region of ground deformation during and after an earthquake corresponds roughly to the region of major aftershock activity but that the region of crustal movement before the earthquake is much broader [Bendefy, 1966]. Premonitory changes were noted as far away as $100 \mathrm{~km}$ from the $M=7.5$ Niigato earthquake. Tilt precursors have been observed more than $100 \mathrm{~km}$ from magnitude 6 and smaller events and at $10 \mathrm{~km}$ from magnitude 4.5 events [Tsuboi, 1958; Hagiwara and Rikitaki, 1967]. Ohtake [1973] observed a $V_{p} / V_{\text {a }}$ anomaly at $175 \mathrm{~km}$ from an impending magnitude 6.5 event and at $75 \mathrm{~km}$ prior to a magnitude 5.3 event.

The San Fernando $V_{p} / V_{s}$ and $V_{p}$ results require a dilatant zone that extends outward from the epicentral area by at least . $80 \mathrm{~km}$ toward the station RVR [Whitcomb et al., 1973].

Few data are available regarding the uplift prior to the 1971 San Fernando earthquake immediately above the hypocenter or in the vicinity of the surface break. However, there are firstorder leveling data about $13 \mathrm{~km}$ from the epicenter that indicate at least $0.1 \mathrm{~m}$ of uplift in the 10 years prior to the earthquake [Castle et al., 1974]. Half of this occurred in the 3 years prior to the event. With the combination of the preearthquake and postearthquake data the anomalous uplift had a diameter of at least $40 \mathrm{~km}$ [Castle et al., 1974]. Kondratenko and Nersesov [1962] reported that the size of the anomalous region was $25 \mathrm{~km}$ prior to a magnitude 3 event. Combining this observation with data from smaller events, they proposed a relationship between anomaly size (diameter) and earthquake energy that can be written as

$$
L=8.1 M-1.8
$$

where $L$ is in kilometers. Other measures of earthquake dimensions, such as aftershock area or fault length, are commonly expressed on physical grounds as power laws. The power law relationship satisfied by the Kondratenko-Nersesov data is

$$
\log L=0.26 M+0.46
$$

which gives $L=69 \mathrm{~km}$ for $M=5.3$ and $L=133 \mathrm{~km}$ for $M=$ 6.4. Although a large extrapolation is involved, these distances are consistent with those required to explain the San Fernando and Japanese observations but are much greater than the dimensions usually associated with earthquakes of this magnitude, such as fault length of aftershock dimensions. For example, using the Utsu and Seki [1955] relationship $\log A=$ $M-4$ for aftershock area $\left(A=l^{2}\right)$ and magnitude $(M)$, we obtain the remarkably simple relation

$$
\log l / L^{2}=-3
$$

with $L$ and $l$ in kilometers.

The size of the 'zone of preparation' for the earthquake 
therefore is much larger than the zone of failure, as is indicated by aftershocks, for earthquakes below $M=9.8$. For a magnitude 5 event the dimension $(58 \mathrm{~km})$ of the anomalous region $(L)$ is about 10 times larger than the dimension of the failure (aftershock) region. For a magnitude 7 event the anomalous region is only 2.5 times larger than the failure region, or $190 \mathrm{~km}$.

It is interesting to note that this relationship predicts equal sizes of the failure zone and anomalous region at $1000 \mathrm{~km}$, a failure zone dimension associated with the largest known earthquakes.

\section{Effect of Pore Fluid on Seismic Velocities}

Nur and Simmons [1969] have demonstrated that wave velocities in low-porosity rocks are dramatically affected by pore fluid properties. Compressional wave velocities are higher in fluid-saturated rocks than in dry rocks, while the shear velocities are about the same. The results can be explained in terms of the Eshelby-Walsh theory of elastic properties of a solid containing ellipsoidal fluid-filled inclusions. Walsh [1969] gives expressions for the elastic constants of a solid containing randomly oriented penny-shaped cracks. We have used his equations below. The effect of aligned cracks, such as one might expect in strongly dilatant rock, has been calculated by Anderson et al. [1974]. An alternate way of looking at the crack problem is currently being investigated by $O^{\prime}$ Connell and Budiansky [1974].

Some numerical experiments giving $V_{p} / V_{s}$ for dry and saturated rocks as a function of porosity $\phi$ and aspect ratio $\alpha$ are given in Table 1. Also given are the velocity changes associated with the change from saturated to dry conditions. Low values of $V_{p} / V_{s}$ require that cracks be dry and that $\alpha \approx \phi$, but there is no constraint on absolute porosity.

The magnitude of the velocity change, going from saturated to unsaturated conditions, increases for a given $\phi / \alpha$ with decreasing $\phi$ or $\alpha$. For example, for the case of $\alpha \approx \phi$ the differences in $V_{p}$ and $V_{B}$ between saturated and undersaturated conditions are 10 and $3 \%$, respectively, for a porosity of $1 \%$ and 17 and $5 \%$ for a porosity of $0.01 \%$. Relative to the porefree aggregate the $V_{p}$ and $V_{s}$ velocities in the dry porous aggregate are decreased by 20 and $14 \%$, respectively, independent of porosity for $\alpha \approx \phi$. Since the seismic data [Whitcomb et al., 1973] indicate that the $V_{p} / V_{s}$ ratio drops more than $10 \%$ in the anomalous period before an earthquake, it appears that the main effect is going from saturated to undersaturated rather than from pore-free dry rock to a dry porous rock as proposed by Nur [1972].

The aspect ratio and porosity can be estimated from the data of Nur and Simmons [1969]' and the equations of Walsh [1969]. A few representative values are given for granite in Table 2. In the calculations we assumed that $K_{\mathrm{H}_{\mathrm{O}}}=23 \mathrm{kbar}$, $K_{1}($ Westerly $)=590 \mathrm{kbar}$, and $K_{1}($ Casco $)=660 \mathrm{kbar}$ and

TABLE 1. Properties of Dry (d) and Saturated (s) Aggregates as a Function of Porosity $\phi$ and Crack Aspect Ratio a

\begin{tabular}{clcccc}
\hline$\phi$ & $\phi / \alpha$ & $\begin{array}{c}\left(V_{p} / V_{s}\right) d \\
\text { Dry }\end{array}$ & $\begin{array}{c}\left(V_{p} / V_{s}\right)_{s} \\
\text { Saturated }\end{array}$ & $\Delta V_{p}, \%$ & $\Delta V_{s}, \%$ \\
\hline 0.0100 & 1 & 1.61 & 1.74 & -10 & -3 \\
0.0050 & 1 & 1.61 & 1.78 & -13 & -4 \\
0.0010 & 1 & 1.61 & 1.83 & -16 & -5 \\
0.0001 & 1 & 1.61 & 1.83 & -17 & -5 \\
0.0010 & 0.1 & 1.71 & 1.73 & -2 & 0 \\
0.0001 & 0.1 & 1.71 & 1.74 & -2 & 0 \\
\hline
\end{tabular}

TABLE 2. Porosity Parameters ( $\phi$ and $\alpha$ ) as a Function of Hydrostatic Pressure $(P)$ for Westerly Granite

\begin{tabular}{rccc}
\hline , bars & $\phi, \times 10^{3}$ & $a, \times 10^{3}$ & $\phi / \alpha$ \\
\hline 0 & 9.5 & 1.7 & 5.6 \\
50 & 7.6 & 3.7 & 2.1 \\
100 & 5.3 & 5.1 & 1.0 \\
200 & 4.4 & 6.9 & 0.6 \\
400 & 2.6 & 5.9 & 0.4 \\
700 & 1.4 & 4.6 & 0.3 \\
1000 & 0.9 & 4.0 & 0.2 \\
2000 & 0.8 & 8.1 & 0.1 \\
3000 & 0.4 & 6.8 & 0.1 \\
& & & \\
\hline
\end{tabular}

It is assumed that $K_{1}=590 \mathrm{kbar}, \lambda_{0}=\mu_{1}$ (i.e., $\sigma_{1}=$ 0.25 ), $K_{2}=23 \mathrm{kbar}$ (saturated), and $K_{2}=0$ (dry). Values are calculated from ultrasonic data of Nur and Simmons [1969].

that the Poisson's ratio of the grains was 0.25 . Note that, as expected, the porosity decreases with hydrostatic pressure. The aspect ratio is roughly constant, $\alpha \sim 0.004-0.008$.

Under ambient deep-crustal conditions the properties of the pore fluid, except for viscosity, are close to those of water at normal conditions, but as pore pressure decreases the fluid becomes more 'steamlike,' having low viscosity, low density, and high compressibility [Anderson and Whitcomb, 1973a, b]. Compressional velocity decreases rapidly with pore pressure and fluid bulk modulus. The compressional velocity levels off to a nearly constant value when the pore fluid bulk modulus falls to a value between 1 and $10 \mathrm{kbar}$.

In the dilatancy-diffusion model the recovery phase is due to increasing pore pressure due to the flow of water into the anomalous region. In the crack closure model the recovery in velocities is due to decreased porosity and an increase in fluid velocities due to the reduction of pore spaces, i.e., the reverse of the first part of the anomaly cycle.

This situation can be illustrated in Figure 4 following Anderson and Whitcomb [1973b]. The compressional velocity was calculated on the assumptions that properties of the rock matrix are constant and the crack aspect ratio is constant ( $\alpha=$ 0.005 ) for two initial porosities $(0.1$ and $0.2 \%)$ and on the assumptions concerning the change of pore pressure with porosity that (1) for an open system, pore pressure $P_{p}$ is constant and (2) for a closed system, pore pressure is a calculable function of porosity. The variation of pore pressure and pore fluid bulk modulus in the closed system case is given in the lower two panels of Figure 4. In the open system the velocity decreases slowly with porosity (dashed curves in Figure 4). In the closed system, when new fluid is not available to fill the newly created void space, the velocities decrease rapidly with porosity.

In the initial stages of dilatancy the pore pressure and bulk modulus are relatively constant (points 1 and 2 in Figure 4), and the velocity decreases slightly. In the period of accelerated dilatancy, pore pressure drops, causing the velocity to drop from points 2 to 3 . A further increase of porosity leads to a large further decrease of velocity. We assume that fluid, after point 4 , can flow into the anomalous region, and this leads to increasing velocity, even if porosity continues to increase. When the pore pressure rises to some critical value, fracture or slippage ensues.

The arrows in Figure 4 schematically indicate the crack closure model. Velocities increase in this model due to a decrease in porosity. Crack closure, of course, increases the pore pressure and raises the bulk modulus of the fluid. The 


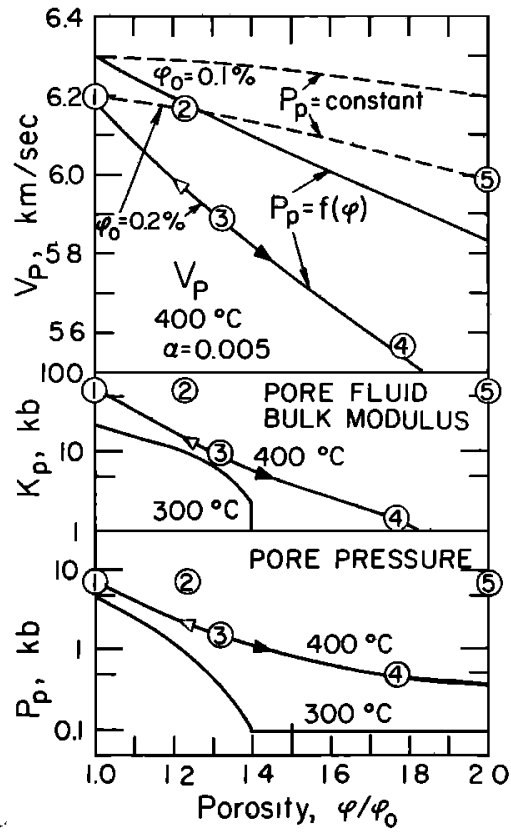

Fig. 4. For the dilatancy-diffusion model the upper panel gives the compressional velocity of granite as a function of porosity for two starting porosities $(0.1$ and $0.2 \%)$ and two assumptions about pore pressure; $\alpha$ is the aspect ratio of the cracks. The circled numbers are successive stages in dilatancy for granite having an initial porosity of $0.2 \%$. The middle panel gives the pore fluid bulk modulus as a function of porosity and temperature. The lower panel shows how the pore pressure changes with porosity. Open arrows indicate the behavior of the crack closure model.

effective stress also decreases in this model and weakens the rock just prior to ultimate failure.

\section{Constraints on Porosity and Porosity Change}

In the dilatancy model it is assumed that the velocity drop is due to the opening of new dry cracks [Nur, 1972] or to the widening of preexisting saturated cracks [Whitcomb et al., 1973]. In the latter case the reduction in velocity is attributed to undersaturation; i.e., part of the pore volume is occupied by vapor. This implies that the pore pressure just prior to the onset of the velocity anomaly is close to the vapor pressure if crustal temperatures are less than the critical temperature of water $\left(374^{\circ} \mathrm{C}\right.$; at this temperature the critical pressure is 218 bars). Such low pore pressures are presumably the result of prior dilatancy, which has only a small effect on velocity as long as the pores remain saturated. Uplift, however, will occur during this stage.

The total increase in porosity is constrained to be small by the following argument. The increase in pore space must manifest itself in uplift and crustal stretching (opening of joints). If the effects are spread out over a large area, they may be difficult to detect, but in the case of the San Fernando earthquake they were certainly less than $1 \mathrm{~m}$. If $10 \mathrm{~km}$ is taken as the thickness of the dilatant layer, the vertical volume strain must be less than $10^{-4}$. The volume strain $\Delta V / V$ is related to the initial porosity $\phi_{0}$ and pore volume strain $\Delta v / v$ by

$$
\Delta V / V=\phi_{0} \Delta v / v
$$

Typical values of crack porosity at failure are 0.4-1.0\% [Brace et al., 1966]. Therefore $\Delta v / v<3 \%$, and $\Delta \phi<3 \times 10^{-4}$. The available 'new porosity' for the onset of the velocity anomaly is therefore of the order of $3 \times 10^{-4}$, or $0.03 \%$. This in turn suggests that pore pressure just before the onset of the velocity anomaly is near a steep portion of the $P-V$ curve for water (Figure 5), so that a small volume change can lead to a large drop in bulk modulus. For crustal temperatures this requires that $\boldsymbol{P}_{p} \ll 500$ bars. It is clear that observed crustal deformations provide strong constraints on the initial state of wet rock undergoing dilatancy if a velocity anomaly is to be observed.

In the dilatancy-diffusion hypothesis, two physical parameters of the crust are important. The porosity increase required for undersaturation must be adequate to explain both decrease in velocity and increase in permeability. If permeability is high during the whole of the dilatancy period, the new crack porosity will remain saturated, and no velocity anomaly will result. On the other hand, if permeability is low throughout this period, no recovery will occur. Therefore an additional constraint on the dilatancy-diffusion hypothesis is that the porosity increase required to explain the velocity drop be adequate to explain the recovery behavior. Permeability must be low enough prior to the accelerated dilatancy period to permit undersaturation. Permeability after the onset of accelerated dilatancy must be high enough to be consistent with the time scale of the recovery process.

Empirically and theoretically, permeability is approximately proportional to $\phi^{8}$. For low-porosity rocks the relative change in bulk modulus is approximately proportional to relative changes in porosity. Since most of the decrease in $V_{p}$ is due to a decrease in $K$, we can write

$$
\frac{d k}{k} \sim \frac{6 \partial V_{p}}{V_{p}}
$$

This is consistent with the measurements of Short [1966]. A $20 \%$ decrease in compressional velocity leads to more than a doubling of the permeability and consequently a halving of the time scale for diffusive equilibrium.

\section{SUMMARY}

There seems to be little doubt that cracks are involved in the onset of the velocity anomaly before earthquakes. The results of this paper verify our earlier work that the $V_{p} / V_{s}$ anomaly is due primarily to a drop in $V_{p}$ and demonstrate that it is probably a path rather than a source effect. We have also shown that the widening of saturated cracks rather than the opening of dry cracks is probably the main cause. Purely elastic effects such as decrease in tectonic stress or increase in effective stress can be ruled out. The total increase of crack

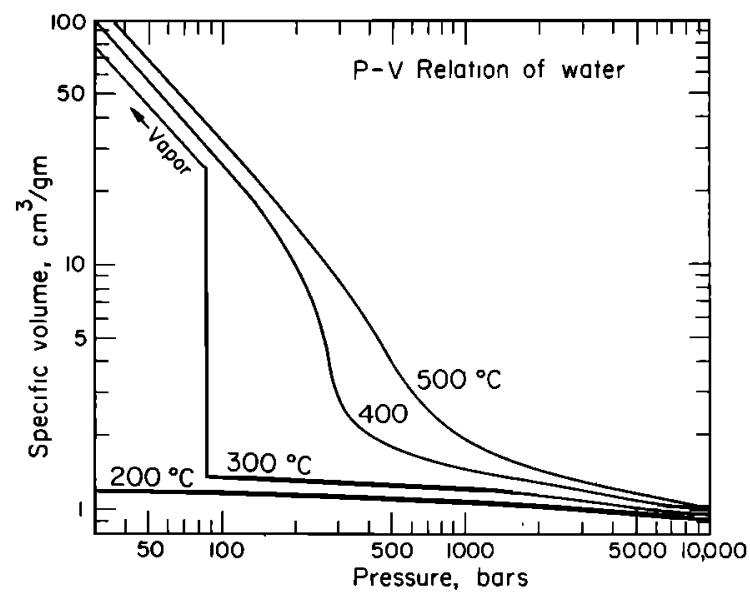

Fig. 5. Equation of state of water from Kennedy and Holser [1966]. The critical temperature, pressure, and specific volume are $374.2^{\circ} \mathrm{C}$, 218.3 bars, and $3.07 \mathrm{~cm}^{3} / \mathrm{g}$. 
porosity is constrained to be small, and the cracks must have small aspect ratios. Pore pressures just prior to the onset of the velocity anomaly must be small, and the permeability must increase substantially if the diffusion recovery mechanism is to hold. The inferred properties of crystalline rock at failure, such as velocity, porosity, and permeability, are reasonable when they are compared with laboratory data and with in situ measurements of the rate of migration of pore fluids. Estimates of permeability are not inconsistent with those required to explain the recovery time scale.

However, crack closure is also a viable mechanism for explaining the velocity recovery. The decrease in porosity and increase in the fluid bulk modulus would cause the velocities to recover and the effective stress to decrease, thereby weakening the rock. However, uplift, gravity, and resistivity changes during the recovery cycle would be different in this model from those in the diffusion model.

We have shown that $t \sim L^{2}$ behavior is also expected in circumstances where fluid flow need not be the dominant process.

There are several important implications of the dilatancy model. If the crust is saturated with water and under hydrostatic pressure, considerable dilatancy must occur before the onset of the velocity anomaly. The large amount of uplift associated with this prior dilatancy is probably unacceptable, which means that the crust is not saturated or that water pressures are always low. Crustal uplift considerations restrict the amount of new porosity and demand a low aspect ratio (narrow cracks). From laboratory evidence and numerical calculations of dilatancy the velocity anomaly can be expected to be anisotropic. Narrow vertical cracks would be most effective in explaining the presently available seismic data. This would suggest in the diffusion model of velocity recovery that vertical transport of water is important.

Acknowledgments. This research was supported by the National Science Foundation grant NSF GA 29920 and grants from the Jet Propulsion Laboratory and Standard Oil Company of California. We appreciate conversations with $\mathbf{R}$. O'Connell and B. Budiansky and a preprint kindly provided by B. Brady in advance of publication. Contribution 2363, Division of Geological and Planetary Sciences, California Institute of Technology, Pasadena, California.

\section{REFERENCES}

Aggarwal, Y. P., L. R. Sykes, J. Armbruster, and M. L. Sbar, Premonitory changes in seismic velocities and prediction of earthquakes, Nature, 24l, 101, 1973.

Anderson, D. L., and J. H. Whitcomb, The dilatancy-diffusion model of earthquake prediction, paper presented at 68th Annual Meeting, Seismol. Soc. of Amer., Golden, Colo., April 16, $1973 a$.

Anderson, D. L., and J. H. Whitcomb, The dilatancy-diffusion model of earthquake prediction, in Proceedings of the Conference on Tectonic Problems of the San Andreas Fault System, edited by R. L. Kovach and A. Nur, p. 417, Stanford University Press, Palo Alto, Calif., $1973 b$.

Anderson, D. L., B. Minster, and D. Cole, The effect of oriented cracks on seismic velocities, J. Geophys. Res., 79, 4011, 1974.

Bendefy, L., Elastic, plastic and permanent deformations of the earth's crust in connection with earthquakes, Soumalainen Tiedeakat. Helsinki, Ser. A, 90, 57, 1966.

Brace, W. F., and R. J. Martin III, A test of the law of effective stress for crystalline rocks of low porosity, Int. J. Rock Mech. Mining Sci., $5,415,1968$.

Brace, W. F., and A. S. Orange, Further studies of the effects of pressure on electrical resistivity of rocks, J. Geophys. Res., 73, 5407, 1968.

Brace W. F., B. W. Paulding, Jr., and C. Scholz, Dilatancy in the fracture of crystalline rocks, J. Geophys. Res., 71, 3939, 1966.
Brace, W. F., J. B. Walsh, and W. T. Frangos, Permeability of granite under high pressure, J. Geophys. Res., 73, 2225, 1968.

Brady, B. T., A physical basis for earthquake precursive in dry brittle rocks (abstract), Geol. Soc. Amer. Abstr. Programs, 6, 285, 1974.

Castle, R. O., J. N. Alt, J. C. Savage, and E. 1. Balazs, Elevation changes preceding the San Fernando earthquake of February 9 , 1971, Geology, 2, 61, 1974.

Gutenberg, B., and C. F. Richter, Earthquake magnitude, intensity, energy and acceleration, Bull. Seismol. Soc. Amer., 32, 163, 1942.

Hagiwara, T., and T. Rikitaki, Japanese program on earthquake prediction, Science, 157, 761, 1967.

Hamilton, R. M., and J. H. Healy, Aftershocks of the Benham nuclear explosion, Bull. Seismol. Soc. Amer., 59, $2271,1969$.

Kanamori, H., and W. Chung, Temporal changes in $P$-wave velocity in southern California, Tectonophysics, 23, 67, 1974.

Kennedy, G. C., and W. T. Holser, Pressure-volume-temperature and phase relations of water and carbon dioxide, in Handbook of Physical Constants, Mem. 97, edited by S. P. Clark, Jr., p. 587, Geological Society of America, Boulder, Colo., 1966.

Kondratenko, A. M., and I. L. Nersesov, Some results of a study of changes in the speeds of longitudinal and transverse waves in the focal zone, Physics of Earthquakes and Explosion Seismology (in Russian), Tr. Inst. Fiz. Zemli A kad. Nauk SSSR, 25, 1962. (Engl. Transl., U.S. Department of Commerce, Washington, D. C.)

Nur, A., Dilatancy, pore fluids, and premonitory variations of $t_{s} / t_{p}$ travel times, Bull. Seismol. Soc. Amer., 62, 1217, 1972.

Nur, A., and J. Booker, Aftershocks caused by pore fluid flow, Science, $175,885,1972$.

Nur, A., and G. Simmons, The effect of saturation on velocity in low porosity rocks, Earth Planet. Sci. Lett., 7. 183, 1969.

O'Connell, R., and B. Budiansky, Seismic velocities in dry and saturated cracked solids, J. Geophys. Res., 79, 5412, 1974.

Ohtake, M., Changes in the ratio of compressional to shear wave velocity related with the occurrence of some shallow earthquakes in Japan, J. Phys. Earth, 21, 173, 1973.

Sadovsky, M. A., I. L. Nersesov, S. K. Nigmatullaev, L. A. Latynina, A. A. Lukk, A. N. Semenov, I. G. Simbireva, and V. I. Ulomov, The processes preceding strong earthquakes in some regions of middle Asia, Tectonophysics, 14, 295, 1972.

Savarensky, E. F., On the prediction of earthquakes, Tectonophysics, $6,17,1968$.

Scholz, C. H., L. R. Sykes, and Y. P. Aggarwal, Earthquake prediction: A physical basis, Science, 181, 803, 1973.

Short, N. M., Effects of shock pressures from a nuclear explosion on mechanical and optical properties of granodiorite, J. Geophys. Res., $71,1195,1966$.

Stewart, G. S., Prediction of the Pt. Mugu earthquake by two methods, in Proceedings of the Conference on Tectonic Problems of the San Andreas Fault System, edited by R. L. Kovach and A. Nur, p. 73, Stanford University Press, Palo Alto, Calif., 1973.

Tsuboi, C., On seismic activities in and near Japan, in Contributions in Geophysics, edited by H. Benioff, M. Ewing, B. F. Howell, and F. Press, Pergamon, New York, 1958.

Tsubokawa, I., On relation between duration of crustal movement and magnitude of earthquake expected, J. Geod. Soc. Jap., 15, $75,1969$.

Utsu, T., Magnitude of earthquakes and occurrence of their aftershocks (in Japanese), J. Seismol. Soc. Jap., 10. 35, 1957.

Utsu, T., and A. Seki, A relation between the area of the aftershock region and the radius of the sensibility circle (in Japanese), Zisin, 3 , 44, 1955.

van Poollen, H. K., and D. B. Hoover, Waste disposal and earthquakes at the Rocky Mountain arsenal, Derby, Colorado, J. Petrol. Technol., 22, 983, 1970.

Walsh, J. B., New analysis of attenuation in partially meited rocks, $J$. Geophys. Res., 74, 4333, 1969.

Whitcomb, J. H., J. D. Garmany, and D. L. Anderson, Earthquake prediction: Variation of seismic velocities before the San Fernando earthquake, Science, 180, 632, 1973.

Wyss, M., and D. J. Holcomb, Earthquake prediction based on station residuals, Nature, 245, 139, 1973.

(Received May 10, 1974;

revised November 8, 1974;

accepted November 19, 1974.) 